\title{
The Cultivation of the Core Literacy of English Discipline in Senior High School Based on "Post- Method" Theory
}

\section{Xingyuan Li}

School of Foreign Language, China West Normal University, Nanchong, Sichuan, China

Abstract: The Curriculum Standards for General High School English (2017 edition) (hereinafter referred to as the Curriculum Standards) clearly states that the specific goal of general high school English curriculum is to cultivate and develop students' core qualities such as language ability, cultural awareness, thinking quality and learning ability after receiving high school English education. The cultivation of core literacy is a hot spot in the current research of basic English education. However, most researches are based on traditional English teaching methods and tend to apply traditional teaching methods to experimental studies in primary and secondary school classrooms, and few of them study how to cultivate students' core literacy from a theoretical perspective. This article will discuss the cultivation of core literacy of English discipline based on the "post method" theory proposed by B. Kurumaravadivelu. Meanwhile, advice on cultivation of the core literacy of English discipline in high school based on "post-method" theory will be given.

Key words: post-method; core literacy of English discipline; language teaching

\section{Introduction}

Curriculum standards clearly emphasize that high school English curriculum should cultivate students' core literacy, such as language ability, cultural awareness, thinking quality and learning ability. Thus, cultivating students' core literacy has gradually become a hot spot for study. But most focus on curriculum reform based on core literacy (Wang Qiang, 2015; Chen Yanjun, Liu Dejun, 2016), connotation of core literacy (Cheng Xiaotang, Zhao Siqi, 2016; Xia Guming, 2018) and experimental researches on the application of traditional foreign language teaching method in the context of core literacy. But the cultivation of core literacy of English discipline is rarely studied from theoretical perspective of teaching methods.

\section{Theoretical Overview}

The concept of "core literacy" was first put forward by the Organization for Economic Cooperation and Development (OECD) in 1997. The connotation of "core literacy" is beyond knowledge and skills. It involves how to use and mobilize all cognitive and social resources to solve a complex problem in a specific situation. Curriculum standards point out that the core literacy of a discipline is the concentrated embodiment of the educational value of a discipline, and it is the correct value concept, essential character and key ability gradually formed through discipline learning. Therefore, under the background of new curriculum reform, how to promote high school students' core literacy of English discipline has been an important research subject. Teachers should combine with unique social situation, education organizations, teacher and learner factors to practice and reflect, and put the teaching theory knowledge into practice based on the context, further to

Copyright (C) 2020 by author(s) and Frontier Scientific Research Publishing Inc.

This work is licensed under the Creative Commons Attribution International License (CC BY 4.0).

http://creativecommons.org/licenses/by/4.0/ 
form a set of operable teaching theory.

In the 20th century, there have been various teaching methods, such as listening and speaking method, communicative method, total physical method, silence method, etc. However, there is no all-purpose approach for all English classes. Since language teaching changes as society develops, each teaching method has its unique social background and specific objects to be taught, and has exerted certain influence on language teaching at that time and in the future. As the opposite of the traditional teaching methods, "Post-method" goes beyond a single traditional foreign language teaching method, being associated with specific teaching situation, reflecting the unity of comprehensiveness and flexibility of the method, and it is a dynamic, open and flexible teaching thought. Spolsky (1988) mentioned that "any theory of second language acquisition that is inclined to a single teaching method is wrong." Prabhu (1990) also reckoned that there is no best method, and different methods are suitable for different scenarios. Allwright (1991) presented a plenary report at a conference entitled "The Death of Methods", stressing the relative futility of the existence of methods and the passing of the method era.

The development of related linguistics discipline has played a certain role in promoting the exploration of language teaching. Linguistics and applied linguistics, as the foundations of language teaching, whose deep development of related theories also continually promote the researchers' study on linguistics. Consequently, the exploration of the nature of language and the nature of language learning is bound to cause the thinking about the diversification of teaching methods. Therefore, "post-method" arises at the historic moment. The conclusion that English teaching has entered the postmethodological era has emerged in the academic world at home and abroad (Kumaravadivelu, 2001; Bell, 2003; Zheng Yuqi, Chen Meihua, 2007; Yang Jiao, 2019).

\section{Main Teaching Concepts of "Post-Method"}

Although Kumaravadivelu (1994) connected the "post-method" with foreign language teaching, he did not call it pedagogy, but prudently called it "The Post-method Condition". Kumaravadivelu did not call it the post-method pedagogy until 2001. "Post-method condition" is a sustainable state, which fundamentally reconstructs our view of language teaching and teacher education. It requires us to examine the features and contents of classroom teaching from the perspective of pedagogy and ideology. By remolding the relationship between theory and practice, it promotes the theorization of classroom teaching practice and the practicalization of theoretical knowledge, and emphasizes learner autonomy and teacher empowerment. The post-method teaching concept proposed by Kumaravadivelu (1994) mainly involves three viewpoints, namely three parameters: particularity, practicality and possibility, the repositioning of three roles of participants (learners, teachers and teacher educators), and ten macro strategies: 1. Maximizing learning opportunities; 2. Promoting consultative interaction; 3. Minimizing the difference in perception; 4. Activating intuitive heuristic teaching; 5. Cultivating language awareness; 6. Inputting situational language; 7. Integrating language skills; 8. Promoting learner autonomy; 9. Ensuring social relevance; 10. Raising cultural awareness.

\section{Ways to Cultivate the Core Literacy of English Discipline}

Curriculum standards emphasize the transformation from teacher-centered to student-centered, emphasize learners' discipline subjectivity and autonomy, emphasize teachers' professional development and education research, and emphasize cooperative relationship between educators and teachers. These are in line with the teaching concepts advocated in the "post-method".

\subsection{The cultivation of students' language ability}

Curriculum standards states that language ability goal is owning a certain sense of language awareness and language sense about English, students can use the existing language knowledge in the common specific context comprehensively, 
understand the meaning expressed by the oral and written texts, identify the appropriate expression, thus express meaning and communicate with others through spoken and written discourse.

4.1.1 Cultivate the common language awareness of teachers and students

Language awareness plays a key role in language teaching and learning. Only when teachers and students have some certain language awareness can they acquire the target language better. Teachers' language awareness can help teachers better understand the nature and laws of foreign language teaching and further guide foreign language teaching. To some extent, the cultivation of students' language awareness can reduce their learning burden. The first step to develop language awareness should start cultivating language sense, teachers penetrate cultural elements in the cultivation of language sense to improve the students' language consciousness through specific cultural situation.

\subsubsection{Select real language materials to enhance students' sense of English}

Good English language sense can help improve learners' ability to understand and use the language, but the development of language sense is not overnight, it needs long-term language input and accumulation, so teachers should pay attention to stimulate students' interest and enthusiasm for learning. While selecting language materials, students' physical and mental development rules, interests as well as experiences should be taken into account to stimulate interest in learning, and further to cultivate students' language sense.

4.1.3 Integrate listening, speaking, reading, viewing and writing to develop students' communicative literacy

Curriculum standards emphasize that the integrated training of listening, speaking, reading, viewing, and writing plays a key role in understanding information, emotion and attitude conveyed by oral or written texts. Students can use language knowledge, cultural knowledge they have learnt to start a new oral or written language communication, thus developing students' language communicative literacy, and further to realize the cultivation of students' language ability. However, the design of language practice should consider specific teaching content, context and students' actual situation. Meanwhile, attention should be paid to the cultivation of cultural awareness, thinking literacy and learning ability in the process of listening, speaking, reading, viewing and writing.

\subsection{Cultivation of students' cultural awareness}

Curriculum standards state that the goal of cultural awareness is helping students acquire cultural knowledge, understand cultural connotation, compare cultural similarities and differences, absorb cultural essence, form correct values, strengthen cultural confidence, form good character of self-respect, self-confidence and self-improvement, and have certain ability of cross-cultural communication and dissemination of Chinese culture.

4.2.1 Develop courses with local characteristics in combination with the social background

The curriculum reform of basic education in China implements the curriculum management at the national, local and school levels. As an intermediate way to implement the national curriculum and school-based curriculum, local curriculum is important. The combination of English curriculum setting and development with local curriculum can not only reflect local cultural characteristics, but also carry out targeted teaching according to the actual situation of local students. To truly let the Chinese culture and local culture penetrate into English textbooks, English classes, and then truly to be absorbed by students. Classroom teaching should also pay attention to the importance of combining scene.

\subsubsection{Compare the cultural differences and language use differences between China and the West}

Language is the carrier of culture, and culture is the soul of language. Therefore, language learning can't be separated from culture. Culture occupies a large part in language learning. Students learn a language not only for the purpose of learning language knowledge, but also for the cultural knowledge behind the language. In high school English learning, reading is an essential way to cultivate students' cross-cultural awareness. Furthermore, differences between China and the 
west are not only reflected in culture, but also in language use, teachers should pay attention to cultivating students' ability to use language in daily English writing teaching. In the process of language use, various skills should be integrated.

\subsubsection{Strengthen inter-disciplinary links}

Curriculum standards emphasize the cultivation of all-round individual, exactly, interdisciplinary penetration teaching is an important way to cultivate students' comprehensive qualities. Teacher can integrate specific teaching contents with other disciplines, the ideological and political education, science and technology, sports, art, music, history and culture, current events. Interdisciplinary teaching can not only effectively stimulate students' interest in learning, but also realize the application of what they have learned, enhance their cultural level and improve cultural awareness.

\subsection{Cultivation of students' thinking literacy}

Curriculum standard argues that the goal of thinking literacy is to differentiate specific phenomenon in language and culture, comb, generalize information, construct the new concept, analyze, deduce the logical relationship of information, evaluate various ideas correctly, express views creatively, develop the preliminary ability to use English to carry on the independent thinking and creative thinking.

\subsubsection{Adopt heuristic teaching to cultivate students' logical thinking ability}

Affected by examination-oriented education, the common teaching mode of high school English in English class is infusion teaching, which usually results in dull classroom atmosphere, passive acceptance of knowledge, lack of positive thinking and exploration process, and lack of benign interaction between teachers and students, so the teaching effect is often unsatisfactory. Therefore, teachers should change the classroom teaching mode and adopt the heuristic teaching. High school English teaching is mainly based on textbooks, so teachers should combine the specific teaching contents to create real teaching situation, flexibly set heuristic questions, effectively use group discussion, brainstorming to stimulate students' positive thinking in the process of participation.

4.3.2 Strengthen the consultative interaction to exercise students' ability of innovative thinking

Traditional English classes overemphasize the authority of teachers, which is not conducive to the cultivation of students' divergent thinking ability. Therefore, teachers should change their teaching concepts and strengthen the interaction and communication with students. Consultative interaction can be divided into form of meaning negotiation, formal negotiation, and content negotiation (Liu Lingyan, 2014). Meaning negotiation refers to a positive process of discourse modification and interaction all the participants make to ensure mutual understanding. The formal negotiation aims at the teachers' questioning of students' mistakes to stimulate students' self-correction. Content negotiation is mainly to eliminate the direction of the information gap, and inspire students to think actively step by step. This series of consultative process is not only a kind of communication between teachers and students' interaction, but also a way of promoting students' cognitive development, innovation thinking development and cultivating a good relationship between teachers and students.

\subsection{Cultivation of students' learning ability}

Curriculum standards state: the goal of learning ability is to help students further set up the correct view of English learning, keep the interest in learning English, have clear learning objectives. Meanwhile, they can obtain English learning resources through the multi-channel, allocate learning time and task, choose appropriate strategies and methods, to monitor, evaluate, reflect and adjust their learning content and processes, and gradually improve the awareness and ability of using English to learn other disciplines.

4.4.1 Repositioning the roles between teachers and students to maximize students' learning opportunities

The "post-method" pedagogy emphasizes that students occupy the dominant position in teaching, and teacher, as an 
assist and guide of students' learning, aims to cultivate students' independent learning ability and habits. In class, teachers should design teaching activities flexibly according to students' physical and mental development level and learning situation, to fully mobilize students' learning enthusiasm and participation, and pay special attention to the selection of teaching content and teaching methods. However, teachers should not only assist students in learning, but also concern the improvement of their professional competence.

\subsubsection{Cultivate learners' autonomy and enhance autonomous learning ability}

The key to cultivate learning ability is learner, teachers play a role of scaffolding in the process of students' learning, constructivism emphasizes that students take the initiative to acquire knowledge rather than teachers teach knowledge. Teachers, as helpers, give students the proper support and guidance in the learning process, to teach students different learning strategies, and teach them to learn to learn. Students should be responsible for their own learning, develop good study habits, so as to develop the ability of independent learning.

\section{Conclusions}

The cultivation of core literacy of English discipline reflects the educational value of discipline, however, the key to cultivating core literacy is to realize the "transformation" of classroom. Three parameters, the reposition of three roles of participants and ten macro strategies advocated in the "post-method" pedagogy is quite important to the cultivation of core literacy, but it is not a universal method of teaching, so teachers should combine the specific teaching content, situation and learners to choose proper teaching strategy. Teaching methods, mode, contents and situation, to some certain extent, should be properly adjusted. In the unit teaching, teacher should read and analyze discourse carefully and deeply, and then choose teaching examples in terms of discourse topic, to assist in designing unit integrative teaching activities, stimulate students' learning interest and enthusiasm, finally achieve the formation of students' core literacy of English discipline.

\section{Conflicts of Interest}

The author declares no conflicts of interest regarding the publication of this paper.

\section{References}

[1] Allwright R. L. (1991). The Death of the Method. Revue de Phonétique Appliquée, 99(101): 78-87.

[2] Bell D. (2003). Method and Postmethod: Are They Really So Incompatible? TESOL Quarterly, 37(2): 325-336.

[3] Cheng X.T., Zhao S.Q. (2016). The Essential Connotation of the Core Literacy of English Subject. Curriculum, Teaching Material and Method, 36(05): 79-86.

[4] Chen Y.J., Liu D.J. (2016). Research on the Theoretical Construction of Native English Teaching Based on the Core Competence of English Subject. Curriculum, Teaching Material and Method, 36(03): 50-57.

[5] Kumaravadivelu B. (1994). The Postmethod Condition: Emerging Strategies for Second/Foreign Language Teaching. TESOL Quarterly, 28(1): 27-48.

[6] Kumaravadivelu B. (2001). Toward a Postmethod Pedagogy. TESOL Quarterly, 35(4): 537-560.

[7] Liu L.Y. (2014). The Construction of "Teacher-Student Negotiation and Interaction" Foreign Language Classroom Model. Higher Education Forum, (06): 70-73.

[8] Ministry of Education. (2018). General High School English Curriculum Standards (2017 Edition), People's Education Press.

[9] Prabhu N.S. (1990). There is No Best Method --Why? TESOL Quarterly, 24(2): 161-176.

[10] Sheng J. (2016). The Influence of Post-modernist Educational Thoughts on English Textbooks in Primary and Secondary Schools in My Country. Shanghai Educational Research, (04): 52-57.

[11] Spolsky B. (1988). Bridging the Gap: A General Theory of Second Language Learning. TESOL Quarterly, 22(3): 
377-396.

[12] Wang Q. (2015). From Comprehensive Language Ability to Core Literacy of English Subject -- The New Challenge of High School English Curriculum Reform. English Teachers, 15(16): 6-7.

[13] Xia G.M. (2018). Connotation Analysis of Language Ability as the Core Literacy of English Subject. Journal of Xingyi Normal University for Nationalities, (01): 103-109.

[14] Yang J. (2019). A Brief Talk on English Classrooms in the "Post-Method" Era. Educational Modernization, 6(82): 244-245+247.

[15] Zheng Y.Q., Chen M.H. (2007). On English Teaching in the "Post-Method" Era. Foreign Languages and Foreign Language Teaching, (10): 33-35. 